\title{
REVISAO BIBLIOMÉTRICA SOBRE O RELACIONAMENTO ENTRE STARTUPS E GRANDES EMPRESAS COM FOCO NA INOVAÇÃO COLABORATIVA
}

\author{
Bruna Nunes (Universidade Federal do Paraná - UFPR) brunanunes@ufpr.br \\ Marcelo Gechele Cleto (Universidade Federal do Paraná - UFPR) mgcleto@ufpr.br
}

\section{Resumo}

Atualmente, com uma economia baseada no conhecimento, muitas organizações começam compartilhar experiências com o objetivo de abrirem suas fronteiras para alavancar a troca de informação, de modo a impulsionar e explorar a inovação colaborativa. Nesse contexto, o relacionamento entre startups e grandes empresas pode ser vantajoso para ambas, as empresas se beneficiam do ecossistema inovador no qual as startups estão inseridas e as startups se beneficiam dos recursos provenientes das empresas. No entanto, equilibrar possíveis conflitos de interesses entre as necessidades da empresa e da startup não é uma tarefa fácil. O presente artigo realiza uma análise bibliométrica sobre a produção científica que aborda o relacionamento entre startups e grandes empresas com foco na inovação colaborativa, analisando os principais trabalhos publicados na área, a fim de entender como essas relações são construídas, geridas e, se de alguma forma, podem contribuir com interações futuras.

Palavras-Chaves: Startup; Inovação Colaborativa; Inovação aberta; Relação interorganizacional; Empreendedorismo

\section{Introdução}

A inovação colaborativa é importante para o sucesso de muitas empresas (DOOLEY; KENNY; CRONIN, 2016), pois baseia-se no uso inteligente de todos os recursos possíveis, incluindo colaborações com partes externas à empresa, permitindo a incorporação de soluções em forma de produtos, serviços ou tecnologias que não poderiam ser geradas pela organização por conta própria (MERCANDETTI et al., 2017). A inovação aberta encoraja as empresas a usar ideias internas e fontes externas de conhecimento para avançar em sua produção de inovação (CHESBROUGH, 2003). Diante deste movimento, startups e grandes empresas buscam interagir, ao fazer isso, as startups recebem ajuda para melhorar a execução de seus processos e as corporações recebem suporte para buscar inovação (LAAGE-HELLMAN; LANDQVIST; LIND, 2018). 
Segundo a Radiografia do Ecossistema Brasileiro de Startups 2017, realizada pela ABStartups e Accenture (2017), 77\% das startups focam em clientes corporativos, ou seja, negócios business-to-business (B2B). As startups perceberam que é mais benefício em trabalhar com as grandes empresas do que em competir com elas. A colaboração interorganizacional no desenvolvimento de inovação é um tópico importante tanto para gerentes quanto para pesquisadores acadêmicos (LAAGE-HELLMAN; LANDQVIST; LIND, 2018).

No entanto, os desafios para a inovação colaborativa entre grandes empresas e startups são enormes (KOHLER, 2016). E embora seja um interesse geral promover a inovação, companhias de setores tradicionais precisam conciliar essa agenda com seus processos internos, complexas cadeias de suprimentos e grandes estruturas físicas (USMAN; VANHAVERBEKE, 2017). Por outro lado, as startups que conseguem acesso a uma grande corporação podem sentir dificuldades em se adequar aos processos da grande empresa, para que então consiga de fato implementar suas soluções inovadoras (KOHLER, 2016).

A inovação colaborativa pode trazer muitas vantagens competitivas para as empresas, por exemplo: encurtar o tempo de lançamento de um novo produto no mercado e minimizar os riscos de inovação (DOOLEY; KENNY; CRONIN, 2016). No entanto, algumas relações colaborativas não trazem os benefícios esperados, ou até mesmo entram em colapso (LV; QI, 2019). Tendo em vista que processo de inovação colaborativa é tecnicamente complexo e que o resultado é muitas vezes incerto, é ressaltada a importância de estudar as interfaces desse relacionamento com o foco na inovação colaborativa visando minimizar esses conflitos.

As relações entre empresas com a finalidade de desenvolvimento de novos negócios, geram interações entre diferentes atores (LAAGE-HELLMAN; LANDQVIST; LIND, 2018). Tendo em vista que esse fenômeno é impulsionador de inovações, faz-se importante compreender como a literatura está abordando as interações entre startups e grandes empresas. O presente artigo realiza uma análise bibliométrica sobre a produção científica que aborda o relacionamento entre startups e grandes empresas com foco na inovação colaborativa, analisando os principais trabalhos publicados na área a fim de entender como essas relações são construídas, geridas e, se de alguma forma, podem contribuir com interações futuras.

\section{Fundamentação teórica}

O termo startup, segundo a Associação Brasileira de Startups (ABStartups) (2019), é usado para designar as empresas que estão em estágio inicial e possuem um modelo de negócios 
escalável e repetível, geralmente ligado à inovação tecnológica, desenvolvido a custos menores, processos mais ágeis e em condições de alto risco e incerteza. O Serviço Brasileiro de Apoio às Micro e Pequenas Empresas (SEBRAE) (2019) define as startups como um grupo de pessoas iniciando uma empresa, trabalhando com uma ideia diferente, escalável e em condições de extrema incerteza.

Segundo Blank (2013) algumas características são inerentes a uma startup e fazem parte do seu DNA: modelo de negócios, escalabilidade, repetibilidade e cenário de incertezas:

- Modelo de negócio: refere-se a forma como irão se relacionar com o mercado (clientes, fornecedores, obtenção de receita, entre outros), além de como uma empresa irá criar e entregar valor.

- $\quad$ Escalabilidade: significa poder atingir rapidamente um grande número de usuários a custos relativamente baixos. A receita cresce em ritmo acelerado à medida que os custos se mantêm ou crescem em ritmo mais lento, fazendo com que a margem seja cada vez maior, acumulando lucros e gerando cada vez mais riqueza.

- Repetibilidade: ser repetível significa ser capaz de entregar o mesmo produto em escala ilimitada, sem muitas customizações ou adaptações para cada cliente, ou seja, deve ser possível replicar ou reproduzir a experiência de consumo de seu produto ou serviço de forma relativamente simples, sem exigir o crescimento na mesma proporção de recursos humanos ou financeiros.

- Cenário de incertezas: enquanto uma empresa estabelecida já conhece seu públicoalvo e os atributos dos produtos que comercializa, as startups buscam respostas do mercado para um produto ou serviço inovador que esperam vender.

O Brasil vive uma explosão empreendedora. Da necessidade à oportunidade, cada vez mais pessoas têm enfrentado o desafio de empreender (STARTUP BETA BRASIL, 2014). É nesse cenário que o público jovem empreendedor, que antes possuía a ideia, mas muitas vezes não a colocava em prática, encontrou nas startups uma alternativa para abrir seu próprio negócio (OLUGBOLA, 2017).

Mesmo em momentos de crise, o modelo de negócio das startups tem atraído cada vez mais os empreendedores brasileiros. O mercado das startups se manteve em crescimento, sendo um negócio atrativo para quem quer empreender ou até mesmo investir, estima-se que até 2035 as startups brasileiras alcancem o faturamento de 5\% do PIB nacional (ABStartups, 2019). Além 
disso a ABStartups (2019) acredita que o Brasil pode se tonar uma das cinco maiores potências em inovação e empreendedorismo tecnológico.

Os números confirmam essa tendência, em 2012 havia 2.519 (duas mil quinhentas e dezenove) startups cadastradas na base de dados da ABStartups. Em 2019, esse número ultrapassou 12.700 (doze mil e setecentas) empresas cadastradas.

\section{Método}

Para a exploração inicial do tema, foram realizadas buscas por artigos científicos nas bases de dados Scopus, Web of Science e Science Direct, essas bases de dados foram escolhidas porque estão entre as bases multidisciplinares e estão disponíveis para acesso por meio do Portal CAPES.

Os termos de pesquisa utilizados foram: "startup", "start-up", "start up", “open innovation” e "collaborative innovation". Foram consideradas as seguintes combinações: ("startup" OR "start-up" OR "start up") AND (“open innovation” AND "collaborative innovation"). A Tabela 1 apresenta os parâmetros de busca e os primeiros resultados encontrados.

Tabela 1 - Parâmetros de busca

\begin{tabular}{c|c|c|c}
\hline Termo de Busca & Base de Dados & Limites de busca & Resultados \\
\hline \multirow{2}{*}{$\begin{array}{c}\text { ("startup" OR "start-up" OR } \\
\text { "start up") AND } \\
\text { ("open innovation" AND } \\
\text { "collaborative innovation") }\end{array}$} & Web of Science & Tópico & 81 \\
\cline { 2 - 4 } & Scopus & $\begin{array}{c}\text { Título, resumo ou palavras- } \\
\text { chaves }\end{array}$ & 171 \\
\cline { 2 - 4 } & Science Direct & Todo texto & 1056 \\
\hline
\end{tabular}

Fonte: A autora (2019)

Os termos foram utilizados nas buscas de acordo com os parâmetros definidos nas bases de dados informadas, gerando um total de 1308 documentos (passo 1). Em seguida iniciou-se um processo de filtragem nas bases de dados para selecionar publicações relevantes ao tema, visando selecionar os artigos condizentes com a pesquisa, conforme mostra a Figura 1.

O primeiro filtro empregado foi referente ao período de abrangência, com o objetivo manter na pesquisa somente os artigos atualizados, as buscas restringiram-se ao período entre os anos de 2015 e 2019, restando 973 publicações (passo 2). 
O segundo filtro empregado diz respeito ao tipo de documento. Foram considerados somente artigos publicados em revistas científicas, sendo estes artigos de pesquisa ou artigos de revisão bibliográfica, resultando em 786 artigos (passo 3).

Em seguida foram excluídos os documentos repetidos, os artigos foram baixados na extensão de arquivos do tipo BibTex e carregados no software de gerenciamento de referências Mendeley, onde a etapa de exclusão de artigos repetidos foi realizada. Após a realização dessa etapa, permaneceram na busca 733 artigos ( $4^{\circ}$ passo).

Como o termo "start-up" em inglês vem do verbo "começar", "iniciar", foi identificado muitas publicações em outras áreas de conhecimento como biologia, química, energia e outros. Para refinar os resultados quanto ao assunto de interesse, no $5^{\circ}$ passo foi realizado a leitura do título dos artigos, buscando assim excluir trabalhos que não se referem ao termo "start-up" no sentido de modelo de negócio. Restaram 156 artigos.

Em seguida foi lido os resumos dos 156 artigos restantes buscando identificar as publicações que estavam relacionadas com o tema, chegou-se a um montante de 41 resultados ( $6^{\circ}$ passo).

Por fim, foi realizada uma leitura completa dos trabalhos encontrados na etapa anterior. Foram selecionados apenas os artigos que trazem conteúdo sobre startups que de alguma colaboram com grandes empresas no contexto de inovação aberta ( $7^{\circ}$ passo). Assim, 20 artigos foram selecionados para compor a base sobre a qual foi efetuada a análise bibliométrica apresentada na próxima seção.

Figura 1: Fluxograma do protocolo de pesquisa

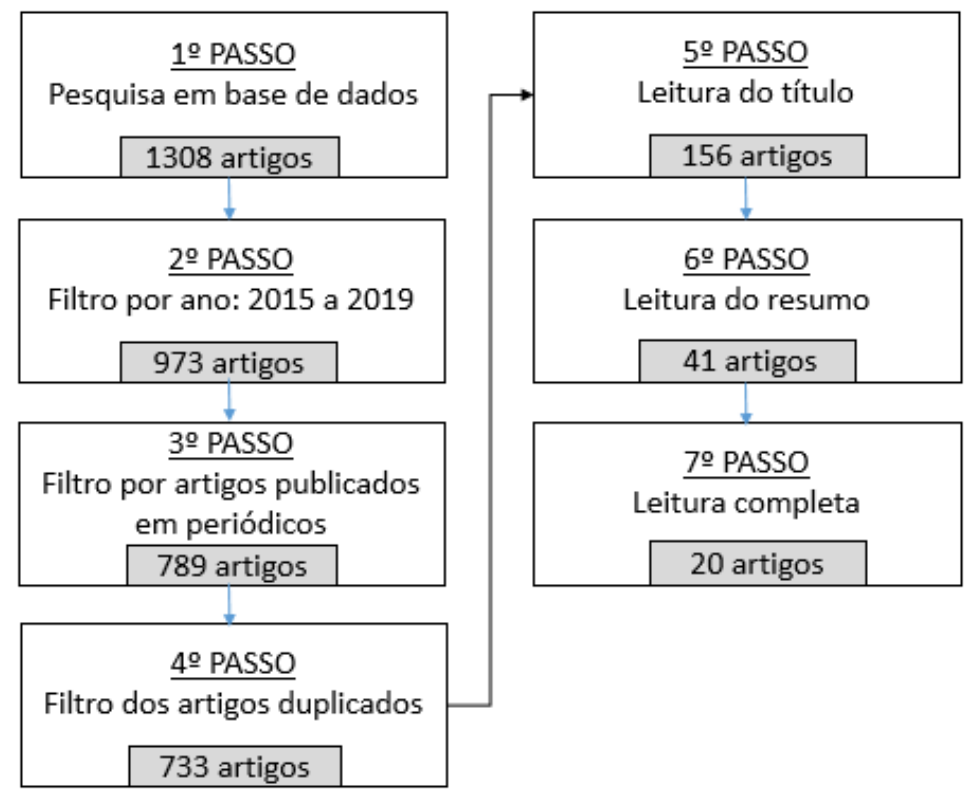

Fonte: a autora (2019) 


\section{Resultados}

Após realizar a revisão sistemática da literatura, o número de publicações encontradas reduziu de 1308 para 20. Sendo possível identificar os artigos mais relevantes sobre o assunto. Os artigos selecionados no fim da pesquisa podem ser observados na Tabela 2, onde também é possível observar o número de citações que cada artigo teve segundo o Google Scholar e a média de citações por ano de circulação. O trabalho de Kohler (2016) é o artigo com maior número de citações, tendo o total de 188 citações, também é o artigo com a maior média de citações por ano, com a média de 47 citações por ano desde a sua publicação.

Tabela 2 - Resultado da pesquisa

(continua)

\begin{tabular}{|c|c|c|c|c|}
\hline Autores & Título & Periódico & $\begin{array}{l}\text { Google } \\
\text { scholar }\end{array}$ & $\begin{array}{l}\text { Média } \\
\text { citações } \\
\text { por ano }\end{array}$ \\
\hline Kohler (2016) & $\begin{array}{c}\text { Corporate accelerators: Building } \\
\text { bridges between corporations and } \\
\text { startups } \\
\end{array}$ & $\begin{array}{l}\text { Business } \\
\text { Horizons }\end{array}$ & 188 & 47,00 \\
\hline $\begin{array}{l}\text { Spender et al. } \\
\quad(2017)\end{array}$ & $\begin{array}{l}\text { Startups and open innovation: a } \\
\text { review of the literature }\end{array}$ & \begin{tabular}{|c|}
$\begin{array}{c}\text { European Journal } \\
\text { of Innovation } \\
\text { Management }\end{array}$ \\
\end{tabular} & 93 & 31,00 \\
\hline $\begin{array}{c}\text { Usman e } \\
\text { Vanhaverbeke } \\
(2017) \\
\end{array}$ & $\begin{array}{l}\text { How start-ups successfully organize } \\
\text { and manage open innovation with } \\
\text { large companies }\end{array}$ & \begin{tabular}{|c|}
$\begin{array}{c}\text { European Journal } \\
\text { of Innovation } \\
\text { Management }\end{array}$ \\
\end{tabular} & 52 & 17,33 \\
\hline $\begin{array}{c}\text { Battistella, } \\
\text { Toni e Pessot } \\
(2017) \\
\end{array}$ & $\begin{array}{l}\text { Open accelerators for start-ups } \\
\text { success: a case study }\end{array}$ & $\begin{array}{c}\text { European Journal } \\
\text { of Innovation } \\
\text { Management }\end{array}$ & 41 & 13,67 \\
\hline $\begin{array}{c}\text { Kupp, Marval } \\
\text { e Borchers } \\
(2017) \\
\end{array}$ & $\begin{array}{l}\text { Corporate accelerators: fostering } \\
\text { innovation while bringing together } \\
\text { startups and large firms }\end{array}$ & $\begin{array}{l}\text { Journal of } \\
\text { Business } \\
\text { Strategy }\end{array}$ & 18 & 6,00 \\
\hline $\begin{array}{l}\text { Michelino et } \\
\text { al. (2017) }\end{array}$ & $\begin{array}{l}\text { Open innovation for start-ups: A } \\
\text { patent-based analysis of bio- } \\
\text { pharmaceutical firms at the } \\
\text { knowledge domain level }\end{array}$ & $\begin{array}{c}\text { European Journal } \\
\text { of Innovation } \\
\text { Management }\end{array}$ & 16 & 5,33 \\
\hline $\begin{array}{c}\text { Hasche, } \\
\text { Linton e } \\
\text { Öberg (2017) }\end{array}$ & $\begin{array}{c}\text { Trust in open innovation - the case of } \\
\text { a med-tech start-up }\end{array}$ & \begin{tabular}{|c|}
$\begin{array}{c}\text { European Journal } \\
\text { of Innovation } \\
\text { Management }\end{array}$ \\
\end{tabular} & 14 & 4,67 \\
\hline $\begin{array}{l}\text { Jackson e } \\
\text { Richter } \\
(2017)\end{array}$ & $\begin{array}{c}\text { Situational logic: an analysis of } \\
\text { open innovation using corporate } \\
\text { accelerators }\end{array}$ & $\begin{array}{l}\text { International } \\
\text { Journal of } \\
\text { Innovation } \\
\text { Management }\end{array}$ & 14 & 4,67 \\
\hline $\begin{array}{l}\text { Richter, } \\
\text { Jackson e } \\
\text { Schildhauer } \\
\text { (2017) }\end{array}$ & $\begin{array}{l}\text { Outsourcing creativity: An abductive } \\
\text { study of open innovation using } \\
\text { corporate accelerators }\end{array}$ & $\begin{array}{l}\text { Creativity and } \\
\text { Innovation } \\
\text { Management }\end{array}$ & 14 & 4,67 \\
\hline
\end{tabular}


Tabela 2 - Resultado da pesquisa

(conclusão)

\begin{tabular}{|c|c|c|c|c|}
\hline Autores & Título & Periódico & $\begin{array}{l}\text { Google } \\
\text { scholar }\end{array}$ & $\begin{array}{l}\text { Média } \\
\text { citações } \\
\text { por ano }\end{array}$ \\
\hline $\begin{array}{l}\text { Hogenhuis, } \\
\text { Van Den } \\
\text { Hende e } \\
\text { Hultink } \\
(2016)\end{array}$ & $\begin{array}{l}\text { When should large firms collaborate } \\
\text { with young ventures? }\end{array}$ & $\begin{array}{l}\text { Research- } \\
\text { Technology } \\
\text { Management }\end{array}$ & 16 & 4,00 \\
\hline $\begin{array}{l}\text { Mahmoud- } \\
\text { Jouini, Duvert } \\
\text { e Esquirol } \\
\text { (2018) }\end{array}$ & $\begin{array}{l}\text { Key Factors in Building a Corporate } \\
\text { Accelerator Capability: Developing } \\
\text { an effective corporate accelerator } \\
\text { requires close attention to the } \\
\text { relationships between startups and } \\
\text { the sponsoring company }\end{array}$ & $\begin{array}{l}\text { Research } \\
\text { Technology } \\
\text { Management } \\
\text { Journal }\end{array}$ & 6 & 2,00 \\
\hline $\begin{array}{c}\text { Gimenez- } \\
\text { Fernandez e } \\
\text { Beukel (2017) }\end{array}$ & $\begin{array}{l}\text { Open innovation and the comparison } \\
\text { between startups and incumbent } \\
\text { firms in Spain }\end{array}$ & $\begin{array}{c}\text { Universia } \\
\text { Business Review }\end{array}$ & 5 & 1,67 \\
\hline $\begin{array}{l}\text { Battistella, De } \\
\text { Toni e Pessot } \\
\quad(2018)\end{array}$ & $\begin{array}{l}\text { Framing Open Innovation in Start- } \\
\text { Ups' Incubators: } \\
\text { A Complexity Theory Perspective }\end{array}$ & $\begin{array}{c}\text { Journal of Open } \\
\text { Innovation: } \\
\text { Technology, } \\
\text { Market, and } \\
\text { Complexity }\end{array}$ & 5 & 1,67 \\
\hline $\begin{array}{l}\text { Marullo et al. } \\
\quad(2018)\end{array}$ & $\begin{array}{l}\text { Ready for Take-off': How Open } \\
\text { Innovation influences startup success }\end{array}$ & $\begin{array}{l}\text { Creativity and } \\
\text { Innovation } \\
\text { Management }\end{array}$ & 4 & 1,33 \\
\hline $\begin{array}{c}\text { Homfeldt, } \\
\text { Rese e Simon } \\
(2019) \\
\end{array}$ & $\begin{array}{l}\text { Suppliers versus start-ups: Where do } \\
\text { better innovation ideas come from? }\end{array}$ & Research Policy & 3 & 0,75 \\
\hline $\begin{array}{l}\text { Moschner et } \\
\text { al. (2019) }\end{array}$ & $\begin{array}{l}\text { Toward a better understanding of } \\
\text { corporate accelerator models }\end{array}$ & $\begin{array}{l}\text { Business } \\
\text { Horizons } \\
\end{array}$ & 3 & 0,75 \\
\hline $\begin{array}{l}\text { Kraus et al. } \\
\quad(2019)\end{array}$ & Open innovation in (young) SMEs & $\begin{array}{l}\text { International } \\
\text { Journal of } \\
\text { Entrepreneurship } \\
\text { and Innovation }\end{array}$ & 1 & 0,25 \\
\hline $\begin{array}{c}\text { Park e } \\
\text { Panagopoulos } \\
\text { (2019) }\end{array}$ & $\begin{array}{l}\text { Patent Protection, Startup Takeovers, } \\
\text { and Open Innovation }\end{array}$ & $\begin{array}{l}\text { International } \\
\text { Journal of the } \\
\text { Economics of } \\
\text { Business } \\
\end{array}$ & 1 & 0,25 \\
\hline $\begin{array}{l}\text { Bereczki } \\
(2019)\end{array}$ & $\begin{array}{l}\text { An open innovation ecosystem from } \\
\text { a startup's perspective }\end{array}$ & $\begin{array}{l}\text { International } \\
\text { Journal of } \\
\text { Innovation } \\
\text { Management }\end{array}$ & 0 & 0,00 \\
\hline $\begin{array}{l}\text { Rocha, } \\
\text { Mamédio e } \\
\text { Quandt } \\
(2019)\end{array}$ & $\begin{array}{l}\text { Startups and the innovation } \\
\text { ecosystem in Industry } 4.0\end{array}$ & $\begin{array}{l}\text { Technology } \\
\text { Analysis and } \\
\text { Strategic } \\
\text { Management }\end{array}$ & 0 & 0,00 \\
\hline
\end{tabular}

Fonte: a autora (2019). 
Os 20 artigos da amostra, foram catalogados e analisados por ano de publicação; por periódicos, por autoria e por países de origem. Adicionalmente, foi apresentada uma nuvem de palavras levando em consideração a frequência de palavras-chaves citadas nos artigos.

O Gráfico 1 apresenta a distribuição das publicações por ano e mostra que entre os artigos selecionados, o auge de publicações foi em 2017, o que demonstra um pico de interesse para o tema. Além disso vale ressaltar que em 2015 não foram encontrados publicação. A revisão da literatura feita por Kraus et al. (2019) já indicava que a colaboração aberta entre startups e grandes empresas iniciaram a partir de 2016, até o ano de 2015 as publicações faziam referência a inovação aberta em pequenas e médias empresas e não em startups.

Gráfico 1: Distribuição das publicações por ano

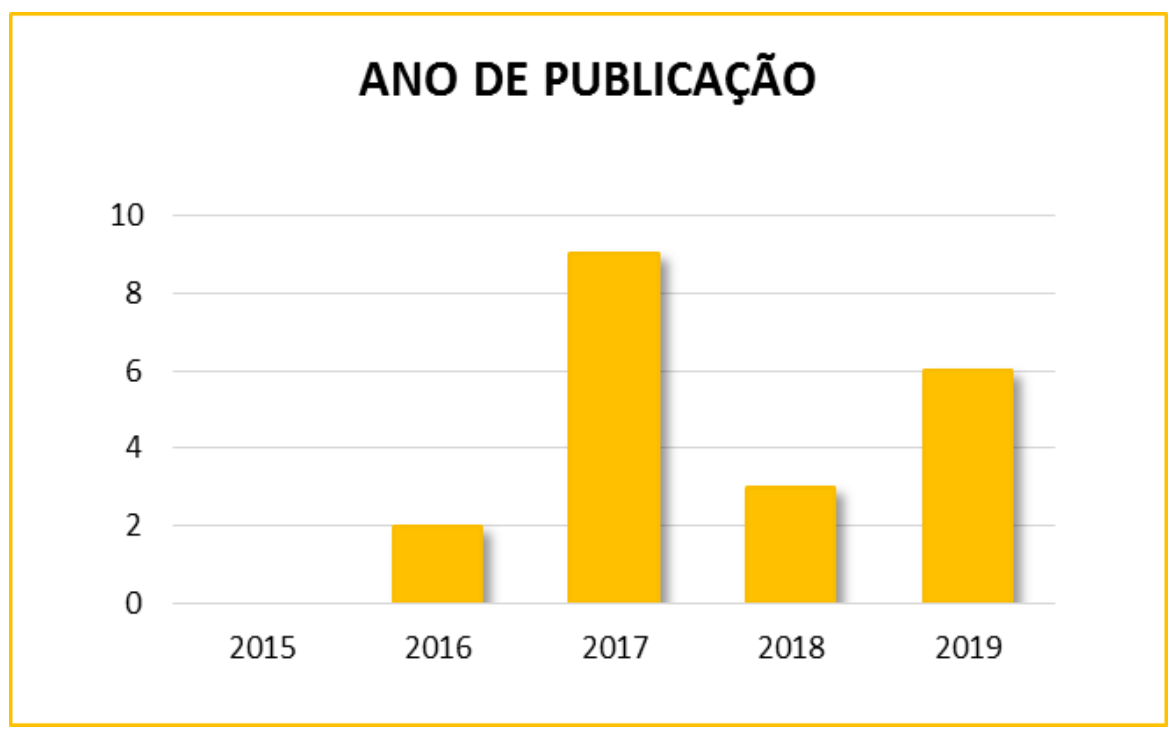

Fonte: a autora (2019).

Também foi realizada uma análise quanto aos periódicos onde os artigos foram publicados. No Gráfico 2 são apresentadas as quantidades de artigos por periódico. O periódico European Journal of Innovation Management aparece como um periódico de destaque dentre os que mais possuem artigos sobre o tema, contemplando cinco publicações. 
Gráfico 2: Distribuição das publicações nos periódicos

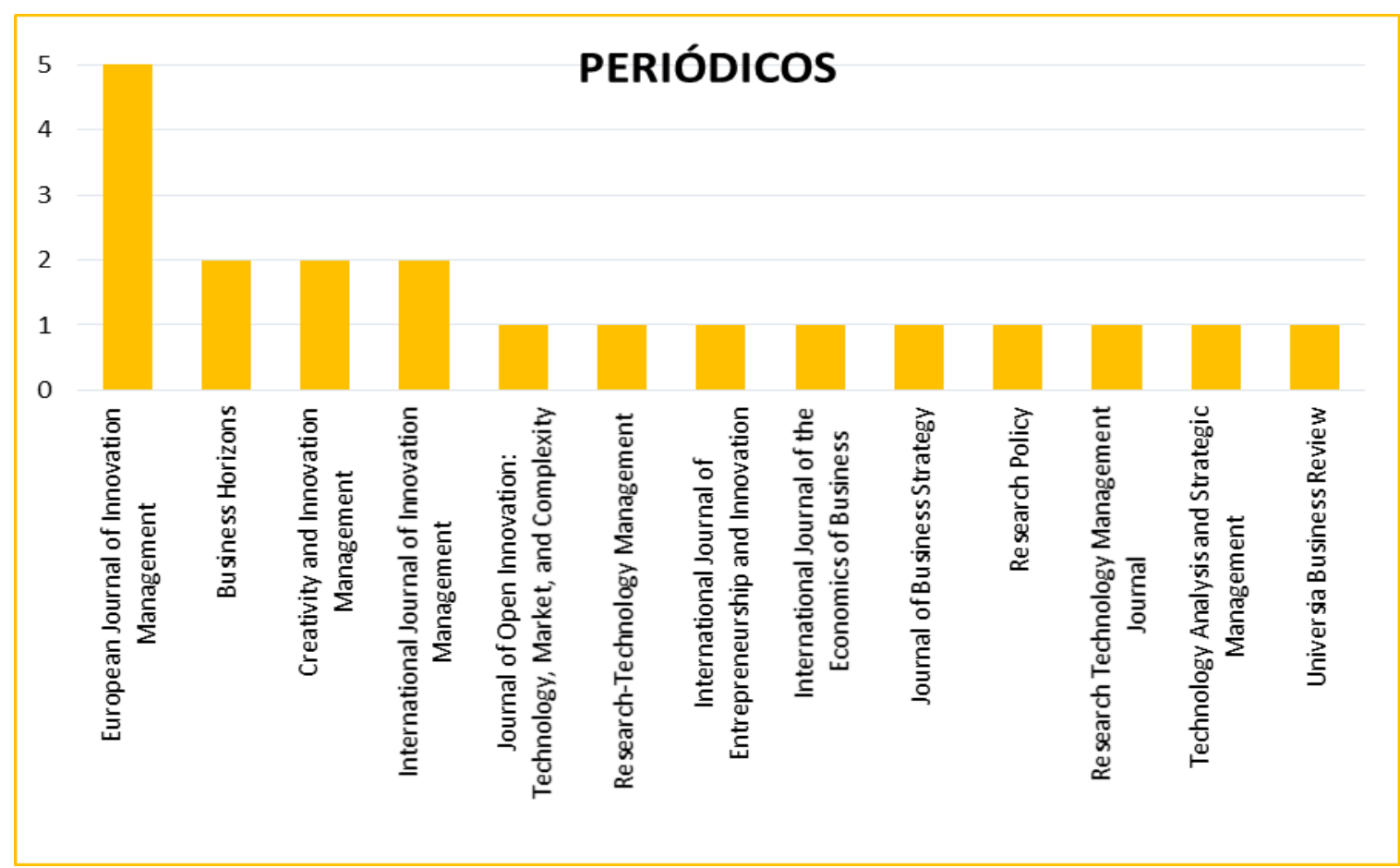

Fonte: a autora (2019).

Com relação à distribuição dos trabalhos por autores, a análise revelou que 53 autores escreveram sobre o tema, mas existem apenas 5 autores com mais de um artigo publicado. $\mathrm{O}$ Gráfico 3 apresenta o número de publicações por autor, devido à grande quantidade de autores, no gráfico expõe apenas os 5 autores com mais de uma publicação e na sequência os dez primeiros autores por ordem alfabética.

Gráfico 3: Distribuição por autor

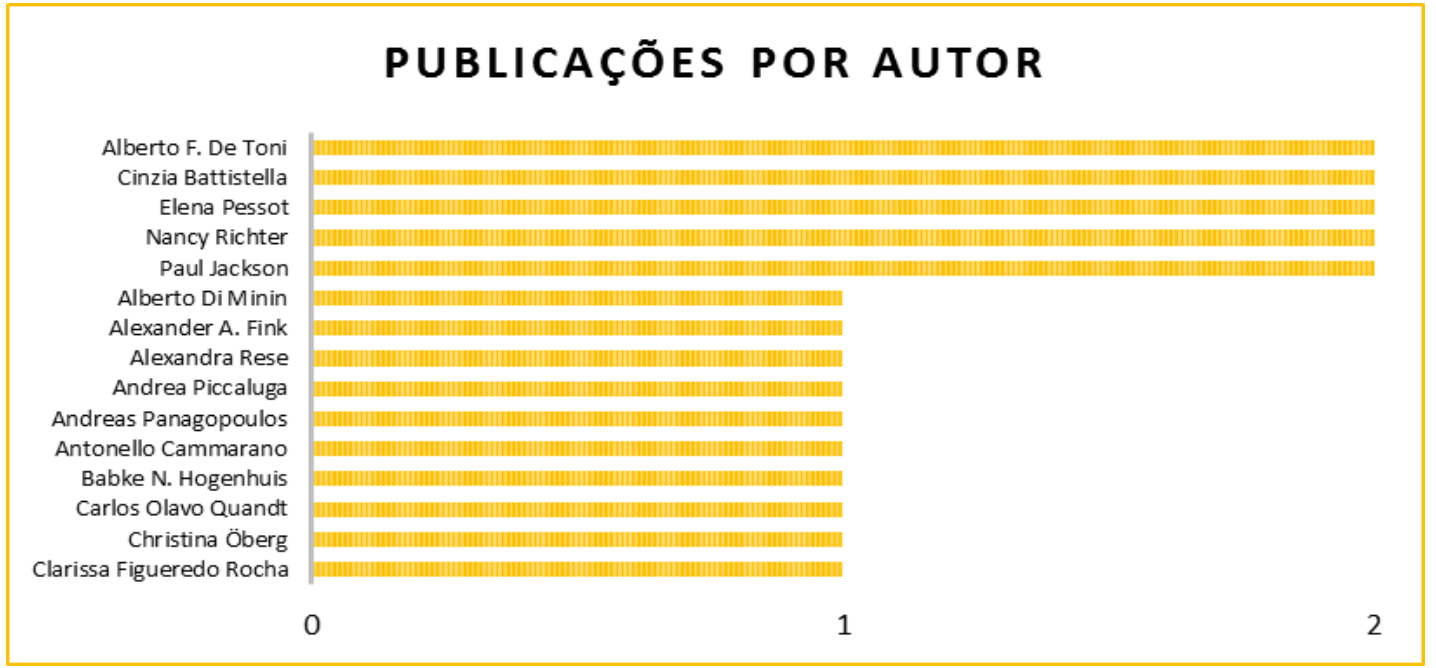

Fonte: a autora (2019) 
Em relação à localização geográfica, o Gráfico 4 apresenta distribuição das publicações por país de origem (utilizou-se o Google Maps para sua representação geográfica). É possível observar um predomínio acentuado de publicações na Europa, sendo a Alemanha e a Itália os países com maior número de publicações.

Gráfico 4: Distribuição das publicações por país de origem

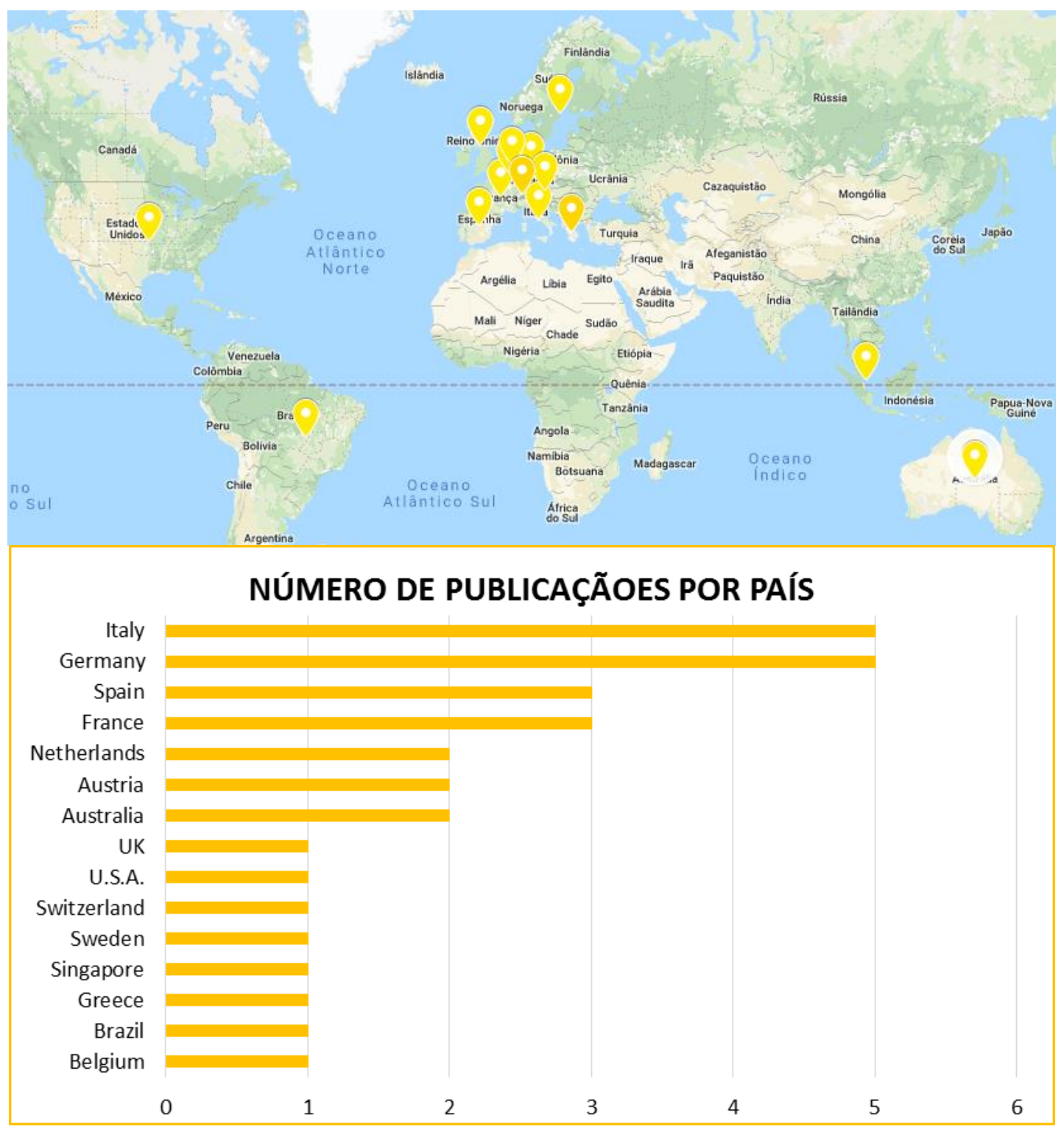

Fonte: a autora (2019)

De forma a verificar os temas mais discutidos nos artigos selecionados foi elaborado, com o auxílio da ferramenta Wordclouds (disponível em www.wordclouds.com), uma nuvem de palavras levando em consideração as palavras-chaves citadas nos 20 artigos da amostra. A nuvem de palavras é uma forma de visualização gráfica de dados que demostra a frequência 
com que as palavras aparecem em determinado contexto. A Figura 2 mostra a nuvem de palavras-chave mais citados pelas publicações, as três palavras-chave com maior frequência são "innovation", “open", "startups", o que demonstra que os artigos selecionados estão de acordos dos objetivos desta pesquisa.

Figura 2 - Nuvem de palavras-chave mais citados pelas publicações

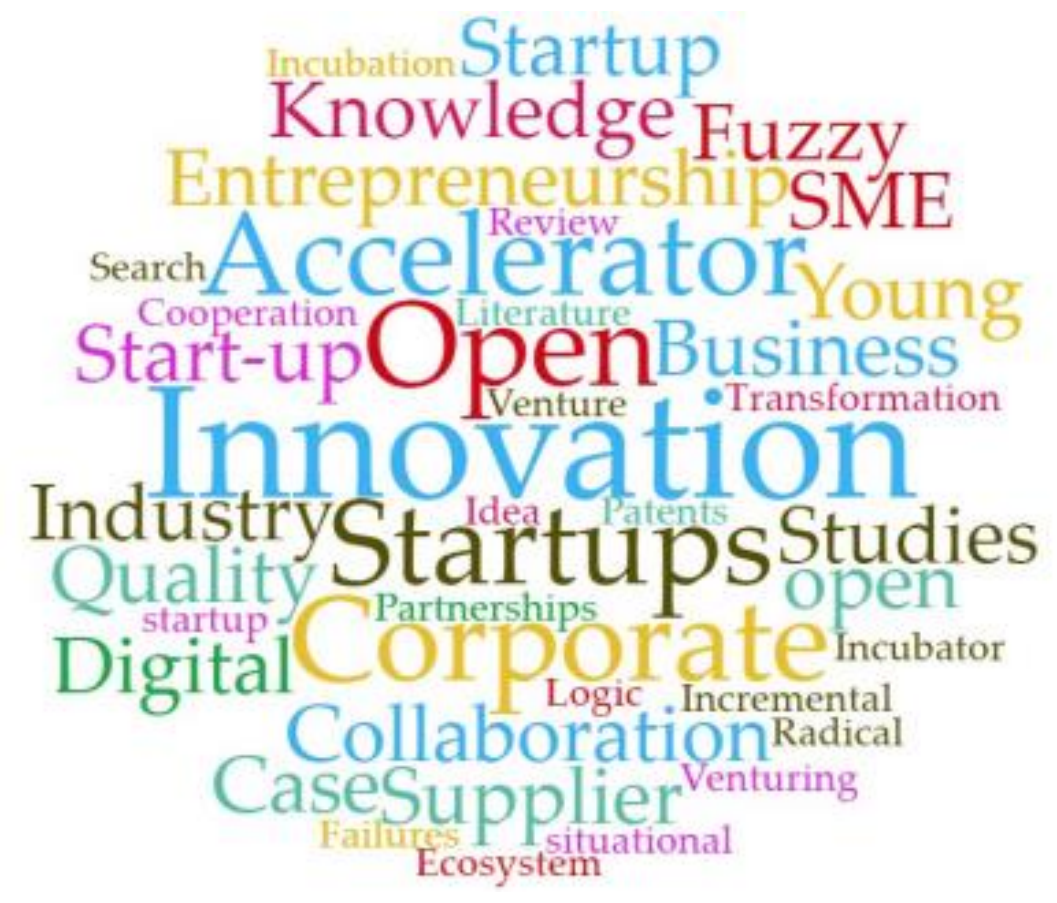

FONTE: a autora (2019)

A pesquisa permitiu verificar que o tema relacionamento entre grande empresa e startups como foco na inovação colaborativa ainda é incipiente em estudos científicos. Os estudos existentes buscam explorar o relacionamento entre startups e grandes empresas, sob a ótica das oportunidades e dos desafios. Os resultados dos trabalhos indicam que para o sucesso da colaboração deve-se levar em consideração:

- Metas transparentes e alinhadas, objetivos de longo prazo, uma equipe independente de defensores de startups, apoio da alta administração (KUPP; MARVAL; BORCHERS, 2017);

- Definição de estratégia, recursos, procedimentos, estrutura, funções e meio ambiente (RICHTER; JACKSON; SCHILDHAUER, 2017); 
- Ao iniciar um processo de colaboração deve-se avaliar as dimensões de design de proposição, processo, pessoas e lugar (KOHLER, 2016);

- Grandes empresas devem considerar o status do projeto no qual buscam colaboração e os recursos que procuram em um parceiro de colaboração (HOGENHUIS, VAN DEN HENDE; HULTINK, 2016);

- A experiência do empreendedor iniciante com a administração em grandes empresas pode ser benéfica para colaboração (USMAN, VANHAVERBEKE, 2017);

- $\quad$ É importante a provisão de: espaço de trabalho colaborativo, rede de consultoria tributária e jurídica, rede de startup, rede de investidores, rede de parceiros de tecnologia e mentoria (BATTISTELLA; TONI; PESSOT, 2017);

- A colaboração poderá ser inibida por conflitos em crenças básicas, proposições, sobre conceitos como autoridade, autonomia e risco, bem como competição por recursos materiais e objetivos pessoais. (JACKSON; RICHTER, 2017);

- $\quad$ As colaborações da inovação aberta podem ser descontinuadas se a confiança não foi totalmente estabelecida. (HASCHE; LINTON; ÖBERG, 2017);

- A falta de recursos financeiros e humanos das startups as leva a abrir suas fronteiras mais do que as empresas já estabelecidas, isso aumenta o desempenho de inovação das startups (BEUKEL; FERNANDEZ, 2017);

- Os cinco serviços presente em incubadoras empresariais, são: infraestrutura física, acesso a fluxos de financiamento, rede de especialistas / empresários, educação / workshops, tutoria e aconselhamento (BATTISTELLA; DE TONI; PESSOT, 2018);

- A quantidade de investimento inicial não tem efeito relevante sobre o sucesso do startup. Um maior esforço no desenvolvimento de novos produtos aumenta significativamente as chances de sucesso das startups. A disponibilidade de propriedade intelectual não é um fator relevante para o sucesso das startups. Equipes que utilizam múltiplas fontes de conhecimento externo têm maior probabilidade de sucesso (MARULLO ET AL., 2018);

- Ideais que surgem das startups são caracterizadas por maior grau de novidade, mas, são menos propensas a serem implementadas do que as ideias incrementais (HOMFELDT; RESE; SIMON, 2019);

- $\quad$ O desenvolvimento de uma estratégia de colaboração aberta com startups é facilitador para as empresas avançarem para a digitalização (ROCHA; MAMÉDIO; QUANDT, 2019). 


\section{Conclusão}

Este estudo apresentou uma análise bibliométrica sobre o relacionamento entre startups e grandes empresas com foco na inovação colaborativa. Apesar de ter se tornado um assunto de grande interesse, a produção bibliográfica de artigos que abordam essa interação ainda é pequena, tal fato se justifica por se tratar de um tema bastante recente no meio corporativo e acadêmico.

De forma geral, os estudos relatam que a interação entre grandes empresas e startups possuem dois fatores importantes: os objetivos da interação e as formas como esta interação se concretizará. Apesar das dificuldades, a necessidade de empresas e startups atuarem em conjunto é um fato. As grandes empresas abriram os olhos para as startups e enxergaram a aproximação com esses atores como uma oportunidade de fazer novos negócios, de reinventar seus modelos de negócios e de gerar inovação. Os processos de interação ainda estão sendo construídos e consolidados. As partes envolvidas estão aprendendo a se relacionar, buscando parcerias sólidas e mitigando os riscos associados a essas interações, além disso, os envolvidos possuem o objetivo de extrair os melhores resultados para ambas as organizações.

Os estudos também evidenciaram a presença dos aceleradores corporativos mediando o relacionamento entre grandes empresas e startups. Este fato vem de encontro com o conceito de inovação colaborativa, as corporações têm percebido que não basta investir em pesquisa e desenvolvimento interno, abrir fronteiras através de programas de aceleração corporativa para se beneficiar da capacidade inovativa que startups possuem, tem se tornado uma prática comum às organizações.

Pesquisas futuras serão úteis para fornecer uma compreensão mais aprofundada sobre o relacionamento entre startups e grandes empresas com foco na inovação colaborativa, entender essa interação através de análise de trajetória pode ajudar a esclarecer o impacto das estratégias de inovação aberta no comportamento inovador das empresas.

\section{REFERÊNCIAS}

ASSOCIACAO BRASILEIRA DE STARTUPS. Disponível em: < https://abstartups.com.br/ 2017/07/05/o-que-e-uma-startup/>. Acesso em: 16/11/2019. 
BATTISTELLA C.; TONI A. F. D.; PESSOT E. Open accelerators for start-ups success: a case study. European Journal of Innovation Management. v.20, p.80-111, 2017

BATTISTELLA C.; TONI A. F. D.; PESSOT E. Framing Open Innovation in Start-Ups' Incubators: A Complexity Theory Perspective. Journal of Open Innovation: Technology, Market, and Complexity. v.4, 33, 2018.

BERECZKI, I. An open innovation ecosystem from a startup's perspective. International Journal of Innovation Management. v. 23, p. 1940001, 2017

BLANK, S. Why the lean start-up changes everything. Harvard Business Review. v. 91, p. 63-72, 2013.

CRESWELL, J. W. Projeto de pesquisa: métodos qualitativo, quantitativo e misto. 2 ed. Porto Alegre: Bookman, 2010.

DOOLEY, L.; KENNY, B.; CRONIN, M. Interorganizational innovation across geographic and cognitive boundaries: Does firm size matter? R\&D Management. v. 46, p. 227-2016.

GIMENEZ-FERNANDEZ E. M; BEUKEL, K. Open innovation and the comparison between startups and incumbent firms in Spain. Universia Business Review. v. 55, p. 18-33; 2017.

HASCHE N.; LINTON G.; ÖBERG C. Trust in open innovation - the case of a med-tech start-up. European Journal of Innovation Management. v. 20, p. 31-49, 2017.

HOGENHUIS, B. N.; VAN DEN HENDE, E. A.; HULTINK, E. J. When should large firms collaborate with young ventures? Research-Technology Management. v. 56, p. 39-47, 2016.

HOMFELDT, F.; RESE, A.; SIMON, F. Suppliers versus start-ups: Where do better innovation ideas come from?. Research Policy. v. 48, p. 1738-1757, 2019.

JACKSON P.; RICHTER N. Situational logic an analysis of open innovation using corporate accelerators. International Journal of Innovation Management. v. 21, 1750062, 2017.

KOHLER, T. Corporate accelerators: Building bridges between corporations and startups. Business Horizons. v. 59, p. 347-357, 2016.

KRAUS S.; ET AL. Open innovation in (young) SMEs. International Journal of Entrepreneurship and Innovation. v. 21, p. 1-13, 2019

KUPP M.; MARVAL M.; BORCHERS P. Corporate accelerators: fostering innovation while bringing together startups and large firms. Journal of Business Strategy. v. 38, p. 47$53,2017$.

LAAGE-HELLMAN, J.; LANDQVIST, M.; LIND, F. Business creation in networks: How a technology-based start-up collaborates with customers in product development. Industrial Marketing Management. v.70, p. 13-24, 2018. 
LV, B.; QI, X. Research on partner combination selection of the supply chain collaborative product innovation based on product innovative resources. Computers \& Industrial Engineering. v. 128, p. 245-253, 2019.

MAHMOUD-JOUINI, S. B; DUVERT, C.; ESQUIROL M. Key Factors in Building a Corporate Accelerator Capability: Developing an effective corporate accelerator requires close attention to the relationships between startups and the sponsoring company. Research Technology Management. v. 61, p. 26-34, 2018.

MARULLO C.; ET AL. Ready for Take-off': How Open Innovation influences startup success. Creativity and Innovation Management. 2018.

MERCANDETTI, F.; ET AL. Innovation by Collaboration between Startups and SMEs in Switzerland. Technology Innovation Management Review. v. 7, p. 23-31, 2017.

MICHELINO F.; ET AL. Open innovation for start-ups: A patent-based analysis of biopharmaceutical firms at the knowledge domain level. European Journal of Innovation Management. v. 20, p. 112-134, 2017.

MOSCHNER ET AL. Toward a better understanding of corporate accelerator models. Business Horizons. v. 62, p. 637-647, 2019.

OLUGBOLA, S. A. Exploring entrepreneurial readiness of youth and startup success components: Entrepreneurship training as a moderator. Journal of Innovation \& Knowledge. v. 2, p. 155-171, 2017.

PARK, I. U.; PANAGOPOULOS, A. Patent Protection, Startup Takeovers, and Open Innovation. International Journal of the Economics of Business. 2019.

RADIOGRAFIA DO ECOSSISTEMA BRASILEIRO DE STARTUPS 2017. Disponível em $<$ https://ecossistemasdestartups.com.br/\#>. Acesso em 21/02/2019.

ROCHA C. F.; MAMÉDIO D. F.; QUANDT C. O. Startups and the innovation ecosystem in Industry 4.0. Technology Analysis and Strategic Management. v. 31, p. 1474-1487, 2019. SERVIÇO BRASILEIRO DE APOIO ÀS MICRO E PEQUENAS EMPRESAS. O que é uma startup? Disponível em: <http://www.sebrae.com.br/sites/Portal Sebrae/artigos/o-que-e-umastartup,6979b2a178c83410VgnVCM1000003b740 10aRCRD>. Acesso em 06/02/2019.

SPENDER, J.; ET AL. Startups and open innovation: a review of the literature. European Journal of Innovation Management. v.20, p. 4130, 2017.

STARTUP BETA BRASIL. Disponível em <http://sebraelikeaboss.com.br/ case2014/wpcontent/themes/sebrae/STARTUP-BETA\%20BRASIL.pdf> Acesso em 14/02/2019.

USMAN, M.; VANHAVERBEKE, W. How start-ups successfully organize and manage open innovation with large companies. European Journal of Innovation Management. v. 20, p. 171-186, 2017. 